\title{
Sentimentos de mães que passaram por situações de urgência e emergência com seus filhos em ambiente domiciliar
}

\author{
Feelings of mothers who have experienced emergency and emergency situations with their \\ children in a home environment
}
Sentimientos de madres que pasaron por situaciones de urgencia y emergencia con sus hijos en ambiente domiciliar

Beatriz Maria dos Santos Santiago Ribeiro ${ }^{1 *}$, Vladimir Araujo da Silva², Elen Ferraz Teston $^{3}$, Victor Hideaki Goto Hirai ${ }^{4}$, Silvia Rocha de Souza ${ }^{5}$ Mariane Cristine Ridão Curty ${ }^{6}$

\section{RESUMO}

Objetivo: Investigar quais os sentimentos mais frequentes em mães que vivenciaram situações de urgência e emergência pediátrica em ambiente domiciliar. Método: Trata-se de uma pesquisa descritiva, de abordagem qualitativa, os dados foram coletados participaram 17 mães no período de dezembro de 2015 a março de 2016, por meio de um formulário sociodemográfico e um roteiro de entrevista que foram gravadas, transcritas, e submetidos à análise de conteúdo. Resultados: Os resultados permitiram identificar após a experiências de acidentes domésticos com seu filho, sentimentos de preocupação, inferioridade, agonia, arrepio, insegurança, desespero, culpa, revolta, pânico, tremor, arrependimento, medo, pavor e aceitação. Conclusão: $A$ enfermagem deve ficar atento às necessidades emocionais das mães, considerando o fato de, muitas vezes, não estarem preparadas para lidar com estas situações, demonstrando sentimentos como culpa, medo, desespero e entre outros.

Descritores: Enfermagem, Mães, Sentimentos.

\section{ABSTRACT}

Objective: To investigate the most frequent feelings in mothers who experienced emergency situations and pediatric emergencies in the home environment. Method: This was a descriptive, qualitative approach, data were collected involving 17 mothers from December 2015 to March 2016, through a sociodemographic form and an interview script that were recorded, transcribed, and submitted to content analysis. Results and discussion: The results allowed to identify after the experiences of domestic accidents with his son, feelings of worry, inferiority, agony, shivering, insecurity, despair, guilt, revolt, panic, tremor, repentance, fear, dread and acceptance. Conclusion: Nursing should be aware of the emotional needs of mothers, considering that they are often not prepared to deal with these situations, showing feelings of guilt, fear, despair and others.

key words: Nursing, Mothers, Feelings.

\section{RESUMEN}

Objetivo: Investigar cuáles los sentimientos más frecuentes en madres que vivenció situaciones de urgencia y emergencia pediátrica en ambiente domiciliar. Método: Se trata de una investigación descriptiva, de abordaje cualitativo, los datos fueron recolectados participaron 17 madres en el período de diciembre de 2015 a marzo de 2016, por medio de un formulario sociodemográfico y un guión de entrevista que fueron grabadas, transcritas, y sometidos al análisis de contenido. Resultados y discusión: Los resultados permitieron identificar después de las experiencias de accidentes domésticos con su hijo, sentimientos de preocupación, inferioridad, agonía, escalofrío, inseguridad, desesperación, culpa, revuelta, pánico, temblor, arrepentimiento, miedo, pavor y aceptación. Conclusíon: La enfermería debe estar atento a las necesidades emocionales de las madres, considerando que a menudo no están preparadas para lidiar con estas situaciones, demostrando sentimientos como culpa, miedo, desesperación y entre otros.

Descriptores: Enfermería, Madres, Sentimientos.

\footnotetext{
${ }^{1}$ Mestranda da Universidade Estadual de Londrina (UEL), bolsista Capes, Califórnia-PR.

* E-mail: beatrizsantiago1994@hotmail.com

2 Cordenador do Curso de enfermagem da Faculdade de Apucarana (FAP), Astorga-PR.

${ }^{3}$ Professora Colaboradora da Universidade Federal de Mato Grosso do Sul, Campo Grande-MS.

${ }^{4}$ Especialista em Medicina do Trabalho, Rolândia-PR.

${ }^{5}$ Enfermeira especialista em nefrologia, Apucarana_PR.

${ }^{6}$ Psicóloga especialista em Saúde Mental Califórnia-PR.
} 


\section{INTRODUÇÃO}

A maternidade é uma das experiências emocionais de maior intensidade para a mulher, em virtude das transformações que vivencia, cujo efeitos são duradouros. A chegada de uma criança representa um novo ciclo para todos os envolvidos. Com o nascimento de uma criança, nasce a esperança que torna possível a concretização de desejos e sonhos ainda não realizados. Pode-se dizer que o processo de cuidar de um recémnascido é uma das experiências mais importantes e enriquecedora do desenvolvimento adulto ( ONGARI , 2013).

A infância é uma etapa da vida que implica em extrema atenção das mães e famílias, haja vista que as crianças são vulneráveis ao meio que as rodeia. Nesse contexto, os incidentes pediátricos possuem inúmeros fatores determinantes: a imitação de tarefas realizadas pelos pais; a curiosidade em buscar novas experiências; a necessidade de explorar o meio; doenças relacionadas à imunidade; conhecimento insuficiente de higiene (SANTOS et al,.2010). Desse modo o ambiente doméstico pode ser um meio que contribuem para a incidência de situações de urgência e emergência pediátricas, uma vez que as crianças se encontram vulneráveis ao meio que as rodeia, necessitando na infância de extrema atenção das mães e seus familiares.

No Brasil os acidentes domésticos envolvendo crianças são causas crescentes de mortalidade e invalidez, e admiráveis fontes de preocupação, constituindo o grupo dominante de razões de morte em crianças a partir de um ano de idade (WAKSMAN et al,.2009). Estima-se que aproximadamente 800 mil crianças são vítimas anualmente de acidentes fatais em todo o mundo (PEDEN, 2009).

Um estudo, analisou a relação entre os sentimentos e a maneira como as mães lidam com o processo supracitado, revelou que o sofrimento admite diferentes dimensões, cuja intensidade varia de acordo com os significados atribuídos à doença, à sua gravidade, à experiência de hospitalização e as implicações desta em sua vida. Nesse contexto, sentimentos como tristeza, desespero, angústia e nervosismo, são expressados de forma intensa pelas mães, caracterizando-se como sofrimento psíquico (COSTA et al,.2009). Sendo assim, há necessidade do desenvolvimento de estratégias que possa minimizar o sofrimento das mães em situações envolvendo seus filhos.

Frente ao exposto, pela escassez de estudo sobre a temática de sentimentos de mães em situações que envolve perigo aos seus filhos, objetivou investigar quais os sentimentos mais frequentes em mães que vivenciaram situações de urgência e emergência pediátrica em ambiente domiciliar. Acredita-se este estudo é relevante para as mães e seus filhos, conhecer tais sentimentos pode contribuir para o estabelecimento de ações educativas que possam ser úteis em situações de urgência e emergência no ambiente domiciliar e, por sua vez, poderá despertar um olhar para as mães que passam por sentimentos intensos

\section{MÉTODOS}

Trata-se de uma pesquisa descritiva, de abordagem qualitativa, que se propõe a encontrar a intensidade com que o fenômeno de interesse ocorre, essa técnica de análise de conteúdo permite seguir uma ordem sequencial em torno de três eixos: a pró-análise, a exploração do material e resultados; inferência e interpretação, desse modo seguimos esses eixos (BARDIN, 2014).

Participaram do estudo 17 mães que vivenciaram situações de urgência e emergência pediátrica com acidentes domésticos. Foram identificadas com o auxílio dos Agentes Comunitários de Saúde (ACS), visto que grande parcela de acidentes domiciliares não são notificados. Os critérios de inclusão: ser mãe de filho que passou por situações de urgência e emergência pediátricas em ambiente domiciliar, ter idade igual ou superior a 18 anos e como critério de exclusão: mães que desistissem de participar da pesquisa após a coleta de dados.

Instrumentos elaborados foram um formulário sociodemográfico que constaram sete perguntas relativas aos dados pessoais e demográficos da mãe e um roteiro de entrevista com nove questões investigando sentimentos vivenciados pelas mães em torno da temática abordada. As visitas foram previamente agendadas, e as entrevistas foram gravadas a duração média foi de 45 minutos a duas horas e 30 minutos e transcritas na íntegra.

A pesquisa foi realizada nas residências das participantes, no município de Califórnia-PR. Os dados foram coletados, individualmente, no período de dezembro de 2015 a março de 2016. As mães foram esclarecidas quanto aos objetivos da pesquisa e convidadas a colaborar. e, posteriormente, apresentado o Termo de Consentimento Livre e Esclarecido (TCLE). Os dados foram coletados, individualmente, no período de dezembro de 2015 a março de 2016. A seguir, foi realizada leitura atenta das respostas a cada uma das questões, a fim de se obter os dados do conjunto e após submetidos à análise de conteúdo, que constitui um conjunto de técnicas que dispõe de procedimentos sistemáticos, com o intuito de descrever o conteúdo dos discursos, subsidiando o conhecimento das palavras e suas significações (BARDIN, 2014).

Concernente aos aspectos éticos, o projeto de pesquisa foi apreciado e aprovado pelo Comitê de Ética em Pesquisa - CETi da Faculdade de Apucarana - FAP, Parecer no 1.365.908, de acordo com a Resolução 466 de 12 de dezembro de 2012, do Conselho Nacional de Saúde/Ministério da Saúde, que dispõe sobre pesquisas envolvendo seres humanos (BRASIL, 2012).

REAS/EJCH | Vol. 11 (1) | e76 | DOI: https://doi.org/10.25248/reas.e76.2019 Página 2 de 6 


\section{RESULTADOS}

Os ACS informaram 20 mães que atendiam aos critérios de inclusão. No entanto, só foi possível entrevistar 17, pois uma delas se recusou a participar, a mesma estava se submetendo à quimioterapia, outra por não ter sido encontrada em sua residência em três tentativas consecutivas, e outra por ter mudado de cidade. Ressaltase que, para evitar a identificação das participantes, optou-se por utilizar a seguinte nomenclatura: M1, M2, M3, até a décima sétima participante,

Identificou-se que a idade média das participantes é de 35 anos (entre 23 anos e 47 anos), 29,4\% são do lar, $64,7 \%$ trabalham com carteira registrada, $28,5 \%$ possuem o ensino médio completo, $70,5 \%$ são casadas e 0 número de filhos teve média igual a três (Quadro 1).

Quadro 1. Caracterização de mães que vivenciaram situações de urgência e emergência pediátrica. Califórnia, PR, 2016.

\begin{tabular}{|c|c|c|c|c|c|c|}
\hline Mãe & Idade & Profissão & Nível de escolaridade & Estado Civil & Religião & $\begin{array}{l}\text { N. de } \\
\text { filhos }\end{array}$ \\
\hline 1 & 29 & ACS & Ensino médio completo & Casada & Católica & 02 \\
\hline 2 & 46 & ACS & Ensino médio incompleto & Viúva & Evangélica & 03 \\
\hline 3 & 38 & $\begin{array}{c}\text { Auxiliar de } \\
\text { Enfermagem }\end{array}$ & Ensino médio completo & Casada & Católica & 03 \\
\hline 4 & 50 & ACS & Superior completo & Casada & Católica & 02 \\
\hline 5 & 30 & Estagiária & Ensino médio incompleto & Separada & Evangélica & 01 \\
\hline 6 & 39 & $\begin{array}{l}\text { Empregada } \\
\text { doméstica }\end{array}$ & $\begin{array}{l}\text { Ensino fundamental } \\
\text { incompleto }\end{array}$ & Casada & Católica & 04 \\
\hline 7 & 37 & Professora & Superior & Casada & Evangélica & 02 \\
\hline 8 & 34 & Do lar & Ensino médio incompleto & Casada & Católica & 05 \\
\hline 9 & 25 & Do lar & $\begin{array}{l}\text { Ensino fundamental } \\
\text { completo }\end{array}$ & Casada & Evangélica & 04 \\
\hline 10 & 42 & Do lar & Ensino médio completo & Casada & Evangélica & 02 \\
\hline 11 & 24 & Do lar & Ensino médio incompleto & Casada & Evangélica & 02 \\
\hline 12 & 29 & Cozinheira & $\begin{array}{c}\text { Ensino fundamental } \\
\text { completo }\end{array}$ & Solteira & Católica & 02 \\
\hline 13 & 23 & Gerente geral & Ensino médio completo & Casada & Católica & 01 \\
\hline 14 & 30 & Recepcionista & Ensino médio completo & Casada & Católica & 01 \\
\hline 15 & 42 & Do lar & $\begin{array}{l}\text { Ensino fundamental } \\
\text { incompleto }\end{array}$ & Casada & Católica & 06 \\
\hline 16 & 47 & Agente de endemias & Ensino médio incompleto & Divorciada & Católica & 04 \\
\hline 17 & 31 & Gerente Comercial & Superior completo & Casada & Evangélica & 01 \\
\hline
\end{tabular}

N, número. Fonte: Autora, 2016

É importante mencionar número de acidentes domésticos descritos foi igual a 21, pois as mães 8,9 e 10 vivenciaram situações de urgência e emergência com mais de um filho. A idade média das crianças, na época dos acidentes, era de três anos e três meses. Os acidentes relatados foram: intoxicação (38\%); engasgo $(28,6 \%)$; queda $(9,5 \%)$; queimadura $(9,5 \%)$; broncoaspiração $(4,8 \%)$; obstrução de vias aéreas por corpo estranho (4,8\%); TCE (4,8\%). Alguns casos resultaram em hospitalizações e procedimentos cirúrgicos, e um deles evoluiu para óbito.

Após análise dos discursos das mães, percebe-se que a maioria reagiu com sentimentos intensos diante das situações de urgência e emergência envolvendo os seus filhos, pois sentiram medo de perdê-los. Nota-se que tal situação não se refere exclusivamente às mães "de primeira viagem", pois o incidente se repetiu com a mesma intensidade nos casos de mães com mais de um filho. 
Quadro 2. Caracterização da idade da criança, tipo de acidente e local de atendimento. Califórnia, PR, 2016.

\begin{tabular}{|c|c|c|c|}
\hline Mãe/Filho* & Idade da criança & Tipo de acidente & $\begin{array}{c}\text { Local de } \\
\text { atendimento }\end{array}$ \\
\hline Mãe 1 & 40 dias & Queda & Hospital \\
\hline Mãe 2 & 7 dias & Engasgo & - \\
\hline Mãe 3 & 6 meses & Queda & UPA \\
\hline Mãe 4 & 3,5 anos & Obstrução de vias aéreas por corpo estranho & Clínica Médica \\
\hline Mãe 5 & 5 anos & Intoxicação por produto de limpeza & Hospital \\
\hline Mãe 6 & 10 anos & Queimadura & Hospital \\
\hline Mãe 7 & 11 dias & Engasgo & UBS \\
\hline Mãe 8/Filho 1 & 4 anos & Intoxicação por veneno de rato & Hospital \\
\hline Mãe 8/Filho 2 & 2 anos e 7 meses & Engasgo & UBS \\
\hline Mãe 9/Filho 1 & 8 meses & Intoxicação por cigarro & Hospital \\
\hline Mãe 9/Filho 2 & 2 anos e 2 meses & Engasgo & UPA \\
\hline Mãe 9/Filho3 & 1 ano e 8 meses & Engasgo & UBS \\
\hline Mãe 10/Filho 1 & 1 ano & Engasgo & UBS \\
\hline Mãe 10/Filho 2 & 11 anos & Queimadura & UBS \\
\hline Mãe 11 & 3 anos & Intoxicação por Clopanazeprezina & UPA \\
\hline Mãe 12 & 6 anos e 6 meses & Intoxicação Porfenobarbital & Hospital \\
\hline Mãe 13 & 3 anos & Intoxicação por Prednisolona & Hospital \\
\hline Mãe 14 & 2 anos & Intoxicação por ácido sulfônico & UPA \\
\hline Mãe 15 & 1 mês e 17 dias & Broncoaspiração & - \\
\hline Mãe 16 & 3 anos e 4 meses & Traumatismo Craniano Encefálico - TCE & Hospital \\
\hline Mãe 17 & 2 anos & Intoxicação por Querosene & Hospital \\
\hline
\end{tabular}

* O número de acidentes descritos foi igual 21, pois as mães 8, 9 e 10 vivenciaram esta experiência com mais de um filho. Fonte: Autora, 2016.

Sobre os sentimentos vivenciados este estudo identificou como preocupação (M1, M2, M7 e M17), inferioridade (M2), agonia (M4), arrepio ( M6), insegurança (M1, M4, M7 e M11), desespero (M1, M4, M7, M9 e M11), culpa (M2, M4, M9, M10, M11 e M13), revolta (M9), pânico (M8), tremor (M8), arrependimento (M9, M10, M11 e M13), medo (M7, M9, M11 e M17), pavor (M7, M11 e M16) e aceitação (M15) como observamos no discursos a seguir:

"Nossa! Eu me senti muito mal, estava desesperada, porque no momento achei que iria perdê-lo. Foi muito difícil". (M1).

"Me senti terrível, a pior mãe do mundo. [...] Tinha acabado de enterrar meu marido há um mês, de repente minha filha estava morrendo também". (M2).

"Me senti desesperada, fiquei agoniada esperando até dar o horário da consulta, com o meu coração na mão.[...] "(M4).

"Muito mal. Quando cheguei eu a vi daquele jeito... Ah, meu Deus! Não gosto de lembrar. Só de te contar, já estou arrepiada [...]" (M6).

"Me senti muito mal, achei que ele fosse morrer na hora. Estava apavorada. Eu não o deixei dormir, falava: Acorda! Acorda! Fala com a mamãe. Ele tinha 11 dias e eu queria que ele falasse comigo. Fiquei muito apavorada na hora. Achei que meu filho fosse morrer. Eu fiquei com medo de ele dormir no caminho até o posto de saúde, pois achei que se tivesse com o olho aberto, estaria vivo, e se fechasse os olhos, não sabia se ele estaria vivo. Foi uma situação muito ruim. No momento do desespero[...]" (M7).

"Nossa, eu não sabia se acudia ele [...] Fiquei em pânico" (M8/Filho 1)

"[..] eu vi que o veneno tinha sido mexido, aí comecei a tremer. (Mãe 8/Filho 1).

"Nossa Senhora! [...] É um susto maior que o outro. [...] A gente fica com medo de perder..." (M9/Filho 2). 
"[...] podia não ter deixado a carteira de cigarro perto dela. É uma coisa que tem que ficar fora do alcance da criança" (M9/Filho 1).

"Fiquei desesperada, sai gritando igual uma louca". (M9/Filho 2)

"A pior coisa do mundo... A gente se sente inútil, porque você ver um filho quase morrendo, e não fazer nada, não conseguir acudir... Poderia ter cortando [...]" (M9/Filho3).

“ "Me senti péssima, pois eu tenho medo de afogamento. Nossa! Eu fiquei apavorada, eu fiquei desesperada. Eu pensava: se eu tivesse levado comigo, não tinha acontecido isso" (M11)

"[...]quando eu acordei ele estava morto". (Mãe 15).

Percebemos outras reações em que as mães gritaram, correram, pediram ajuda espiritual, ou solicitaram ajuda aos parentes e amigos a seguir:

\section{[...]" E sei que foi Deus que me iluminou na hora porque eu mesma não teria essa ideia de socorrê-lo". (M7)}

"Peguei ela, fui na casa da minha tia, gritando, com ela engasgada". (M10)

"Eu fiquei louca, senão fosse meu marido, estar do meu lado, eu não sei se eu ia para o posto, se eu ficava aqui". (M11).

Apreendemos que o atendimento prestado pela equipe de Enfermagem influência nos sentimentos de gratidão (M1) e indignação (M7) como observamos nas falas abaixo:

[...]" Eles foram muito atenciosos. Toda hora eles vinham dar a medicação e perguntavam como ele estava reagindo. Eles me ajudaram bastante ". (M1).

"A enfermeira perguntou se era o primeiro filho, e falou que era normal criança vomitar. Daí eu fiquei sem graça porque era meu primeiro filho. Eu senti que ela estava me humilhando [...] falando com ironia. Falou que eu estava exagerando, quando eu entrei. A enfermeira do lado ficou sem graça por tudo que ela tinha falado, que eu era mãe de primeira viagem, que crianças vomitam mesmo. [...] A enfermeira do posto que me atendeu foi péssima. Eu me senti... nossa! Eu fiquei muito mal. $A$ equipe de Enfermagem que me atendeu, deixou bem a desejar". (M7).

\section{DISCUSSÃO}

Analisando os discursos, percebe-se os sentimentos de mães que passaram por situações de urgência e emergência com seus filhos em ambiente domiciliar, assim investigou os sentimentos mais frequentes vivenciados por essas mães em seu domicilio Algumas mães informaram no presente estudo ter arriscado alguns cuidados em casa, antes de levar as crianças ao serviço de saúde.

Vale destacar que segundo o autor Rati et al., (2013) algumas mães têm dificuldades em diferenciar urgência e emergência, por se tratar de terminologias técnicas. Assim sendo, as mães procuram os serviços de saúde para a solução de suas necessidades, graves ou não, mas que lhe trazem sentimentos de angústia e desconforto. Verifica-se que há uma distância entre o que é urgência para a mãe e o que é para o profissional de saúde. As mães baseiam-se em critérios subjetivos, culturais e sociais, e o profissional de saúde, em discernimentos técnico-científicos

Embora as reações das mães estejam diretamente relacionadas às necessidades e aos pensamentos que as conduziram nas situações de urgência e emergência (RATI et al., 2013), na tentativa de salvar a vida de seus filhos, as fragilidades evidenciadas demonstram o quanto as mães estavam despreparadas para lidar com tais situações, em decorrência da falta de informações. Em contrapartida, algumas falas evidenciam reações que podem caracterizar potencialidades advindas do senso comum e outros sentimentos que podem levar ao sofrimento.

Concernente à espiritualidade, religiosidade ou crenças religiosas, constituem recursos que ajudam a dar significado às experiências de doença, subsidiando suporte social, emocional e espiritual (consolo, motivação e esperança) restaurando as energias e orientando o comportamento dos familiares no processo de adaptação à doença (BOUSSO et al., 2011). As equipes de atendimento podem formular estratégias para promover conforto e acolhimento baseados em planos espirituais para oferecer alivio e conforto as mães quando houver cenários de urgência e emergência com seus filhos em ambiente domiciliar.

Percebe-se que os sentimentos verbalizados - desespero, medo de perder o filho, incapacidade, susto, nervosismo, inutilidade, dificuldade em saber o que fazer para socorrer o seu filho - caracterizam sofrimento para as mães. Com efeito, diante de situações que ameaçam a vida de seus filhos, as mães podem sofrer uma experiência intensa e dolorosa, caracterizada por sentimentos como temor, ansiedade, preocupação, insegurança, sofrimento, desespero e impotência (TOLEDO et al., 2012).

Com efeito, acompanhar um filho no processo de hospitalização é uma tarefa árdua para a mães e o sofrimento vivenciado neste processo pode desencadear o surgimento de transtornos emocionais, 
especialmente quando não existem recursos interiores suficientes para lidar com a angústia e a ansiedade a ele inerentes, e quando é impossível expressar este sofrimento. Observou-se que o estado afetivo das mães, expresso por meio de temor, ansiedade, desespero, impotência, saudade, solidão, preocupação, insegurança, medo e tristeza, está relacionado ao processo de hospitalização e constitui uma resposta emocional adaptativa (COSTA JB et al,.2009).

Trata-se de uma relação dinâmica entre o sofrimento e as estratégias de enfrentamento utilizadas pelas mães, com o intuito de preservar a sua saúde mental. Entretanto, o estabelecimento de uma relação de confiança, respeito e suporte entre os profissionais de saúde e a família, conquistada por meio de uma atitude acolhedora, representa a possibilidade de transformar o ambiente hospitalar, aliviando o sofrimento da criança e de seus familiares (entre os profissionais de saúde e a família) (COSTA; MOMBELLI; MARCON, 2009).

Observa-se que as falas revelam o despreparo das mães em relação aos cuidados necessários com as crianças no ambiente domiciliar, envolvendo alimentação, higienização, segurança e lazer. Nesse contexto, emerge o sentimento de culpa, inerente ao des(cuidado) das mães e à percepção de que poderiam ter evitado tal situação.

Considerando que as mães se sentem responsáveis pelas crianças, a não adoção de medidas de prevenção para evitar a ocorrência de acidentes, propicia o despertar do sentimento de culpa, cuja dimensão é proporcional à gravidade das sequelas desencadeadas. Contudo, os julgamentos punitivos, a elas direcionados, ao considerar o acidente como um momento de descuido, agravam a sensação de culpa (GURGEL, 2014).

Vale lembrar que estabelecer sintonia com uma criança e vir a conhecê-la, constitui uma das tarefas mais difíceis para os pais, cujo aplicabilidade implica em frequentes erros que, por sua vez, integram o jogo dos espelhos da construção das relações. Não obstante, saber corrigir continuamente os próprios erros, parece ser uma virtude importante dos pais (ONGARI,2013). Nessa perspectiva, os profissionais devem auxiliar as mães e demais familiares a reconhecerem os seus erros em relação aos cuidados com a segurança e saúde das crianças.

\section{CONCLUSÃO}

As entrevistadas demonstraram sentimentos, que precisam de apoio e orientações dos profissionais de saúde, necessitando que esses anseios sejam apoiados e esclarecidos, temores e inquietações devem ser considerados. A equipe multidisciplinar carece de construir relacionamentos mais colaborativos, passando a analisar e ponderar as experiências vividas pelas mães, entendendo que cada uma é única e passa por esse processo de maneira diferentes, procurando compreender percepções. Portanto, é necessário compreender percepções conhecendo sua realidade, abrangendo seus sentimentos e significados que atribuem esta existência, analisando como um todo, ofertando apoio emocional, orientação, respeito e ajuda. Com relação ao acolhimento em serviços de saúde, o enfermeiro deve ficar atento às necessidades emocionais das mães, considerando o fato de, muitas vezes, não estarem preparadas para lidar com estas situações, demonstrando sentimentos como culpa, medo, desespero e entre outros. Sugere-se a realização de outras pesquisas, com diferentes métodos investigativos.

\section{REFERÊNCIAS}

1. BARDIN L. Análise de conteúdo. Lisboa: Edições 70; 2014.

2. BOUSSO RS, POLES K, SERAFIM TS et al. Religious beliefs, illness and death: family'sperspectives in illness experience. Rev. Esc. Enferm. USP. 2011; 45(2):391-97.

3. BRASIL. Resolução № 466, de 12 de dezembro de 2012. Conselho Nacional de Saúde. Ministério da Saúde 2012.

4. COSTA JB, MOMBELLI MA, MARCON SS. Avaliação do sofrimento psíquico da mãe acompanhante em alojamento conjunto pediátrico. Estudos de Psicologia.2009, v. 26, n. 3, p. 317-25.

5. GURGEL AKC. Percepção de cuidadores de crianças acerca da prevenção de acidentes domésticos infantis: análise à luz do Modelo de Crenças em Saúde [dissertação de mestrado]. Universidade Federal do Rio Grande do Norte. 2014. 157 f.

6. ONGARI B. O maravilhoso primeiro ano de vida. (tradução: Maria de Lourdes Bontempi Pizzi; revisão técnica: Ana Lúcia Goulart de Faria). Revista Eletrônica de Educação, 2013, v. 7, n. 2, p.257-63.

7. PEDEN M. World report on child injury prevention calls for evidence-based interventions. 2009.

8. RATI RMS, GOULART LMHF, ALVIM CGJ et al. Criança não pode esperar: a busca de serviço de urgência e emergência por mães e suas crianças em condições não urgentes. Ciênc. saúde coletiva, 2013, v. 18, n. 12, p. 3663-72.

9. SANTOS BZ, GROSSEMAN S, SILVA JYB et al. Injúrias não Intencionais na Infância: Estudo Piloto com Mães que Frequentam a Clínica de Bebês da Universidade Federal de Santa Catarina. Brasil. Pesqui. bras. odontopediatria clin. integr., 2010, v. 10, n. 2, p. 15761.

10. TOLEDO ACG, GRAÇA KN, CORTIZO MLC et al. Mães que acompanham os filhos na hospitalização, 2012.

11. WAKSMAN R, GIKAS RC, BLANK D. Prevenção de acidentes na infância e adolescência. São Paulo: Conselho Estadual dos Direitos da Criança e do Adolescente; 2009. 